\title{
Post-kala-azar dermal Leishmaniasis in two different clinical contexts*
}

\author{
Daniel Holanda Barroso ${ }^{1}$ \\ Ana Carolina Depes Perdigao e Vasconcelos ${ }^{1}$ \\ Maria Edileuza Felinto de Brito ${ }^{3}$
}

\author{
Claúdia Elise Ferraz Silva ${ }^{2}$ \\ Silvana Maria de Morais Cavalcanti ${ }^{1}$ \\ Angela Cristina Rapela Medeiros ${ }^{1}$
}

DOI: http:/ / dx.doi.org/10.1590/abd1806-4841.20153373

\begin{abstract}
A bstract: In Brazil, visceral Leishmaniasis is caused by Leishmania chagasi. The development of cutaneous lesions in visceral leishmaniasis patients has been described in two different clinical contexts. Patients with compromised immunity can develop skin lesions as a direct consequence of a current visceral disease. Equally, patients with a history of kala-azar and progressive, immune improvement occasionally develop skin lesions as a consequence of immune reconstitution inflammatory syndrome. These cases manifest in similar fashion to the classic form of post-kala-azar dermal Leishmaniasis. We describe different cases that exemplify these two clinical presentations. Keywords: Dermatology; HIV; Immune reconstitution inflammatory syndrome; Leishmania infantum; Leishmaniasis; Skin diseases
\end{abstract}

\section{INIRODUCTION}

The development of skin lesions in the context of Leishmania sp and HIV co-infection has been described in two different situations. ${ }^{1,2}$ Habitually, cutaneous involvement occurs after starting of highly active antiretroviral therapy (HAART) in the context of immune reconstitution syndrome. ${ }^{1}$ Dermatological lesions can also occur due to a current kala-azar episode. $^{2}$

\section{CASE REPORTS}

\section{Case 1}

A male AIDS sufferer of 6 years, aged 35, needed assistance at the dermatology department during antiretroviral therapy, due to erythematous nodules, some of which were confluent, leading to infiltrated patches with mild scaling that had emerged one year and three months earlier (Figures 1 and 2). The lesions were disseminated. At that point, he did not present systemic signs or symptoms. He had experienced a visceral Leishmaniasis episode four years previously, treated with Amphotericin B, and subsequently underwent prophylaxis with this drug, due to frequent relapses of the disease. Histopathological examination of the skin sample showed amastigote forms of Leishmania sp. The PCR for Leishmania chagasi, using the Primers RV1 and RV2, was positive and the Montenegro's reaction was $14 \mathrm{~mm}$. At the time, the CD4+ cell count was $330 \mathrm{cel} / \mathrm{mm}^{3}$, while the CD4+ cell count was 92cels $/ \mathrm{mm}^{3}$, three months before lesions developed. This patient was treated using Amphotericin B, with complete resolution of skin lesions.

\section{Case 2}

A male, aged 42, HIV-positive for 13 years, undergoing irregular use of antiretroviral therapy, sought assistance due to fever, weight loss and skin lesions that had appeared in the two preceding months. Physical examination revealed disseminated, slightly erythematous papules and nodules, as well as papular lesions on the palate (Figures 3 and 4). He had a 4-year

Received on 15.01.2014

Approved by the Advisory Board and accepted for publication on 30.03.2014

Work performed at the Hospital Universitário Oswaldo Cruz - Universidade de Pernambuco (UPE) - Recife (PE), Brazil.

Financial Support: None.

Conflict of Interest: None.

Universidade de Pernambuco (UPE) - Recife (PE), Brazil.

Universidade Federal de Pernambuco (UFPE) - Recife (PE), Brazil.

Fundação Oswaldo Cruz (Fiocruz) - Recife (PE), Brazil.

(C)2015 by Anais Brasileiros de Dermatologia 


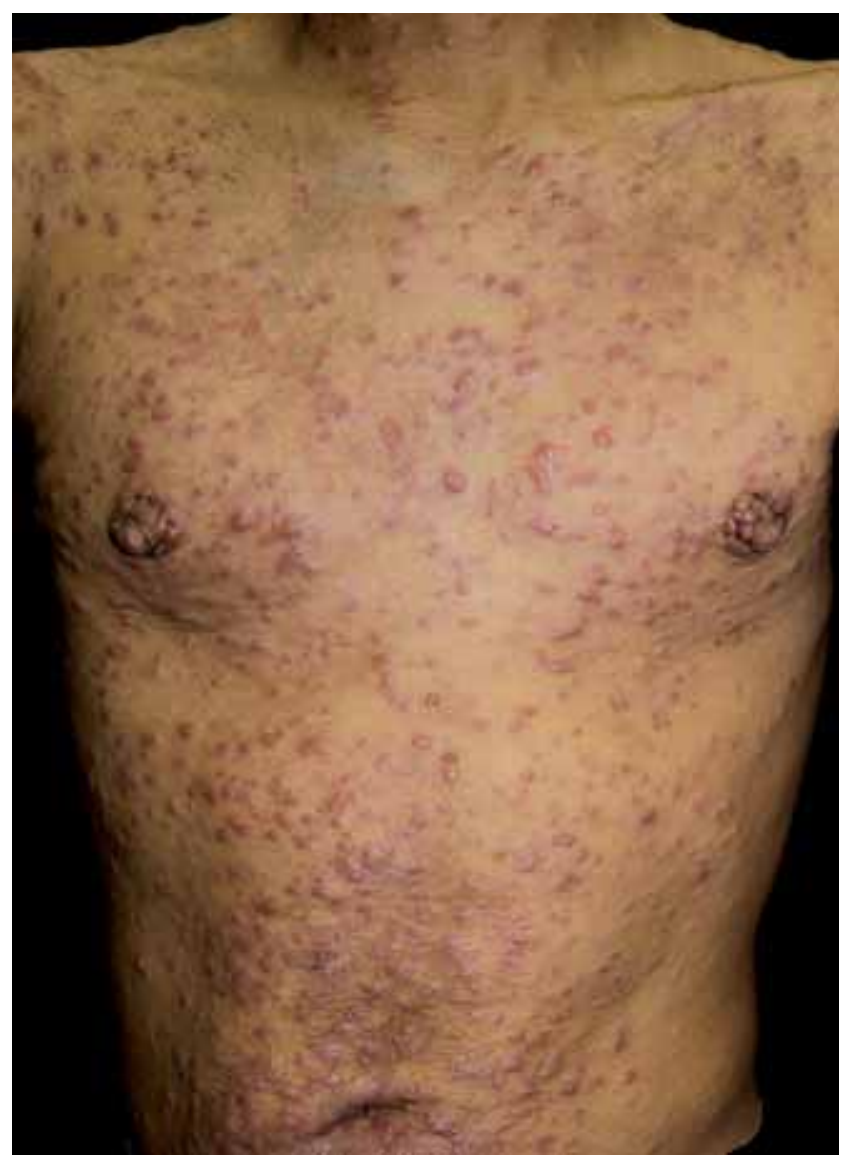

FigURE 1: Papular and nodular lesions on the trunk. They were also present on the extremities and back

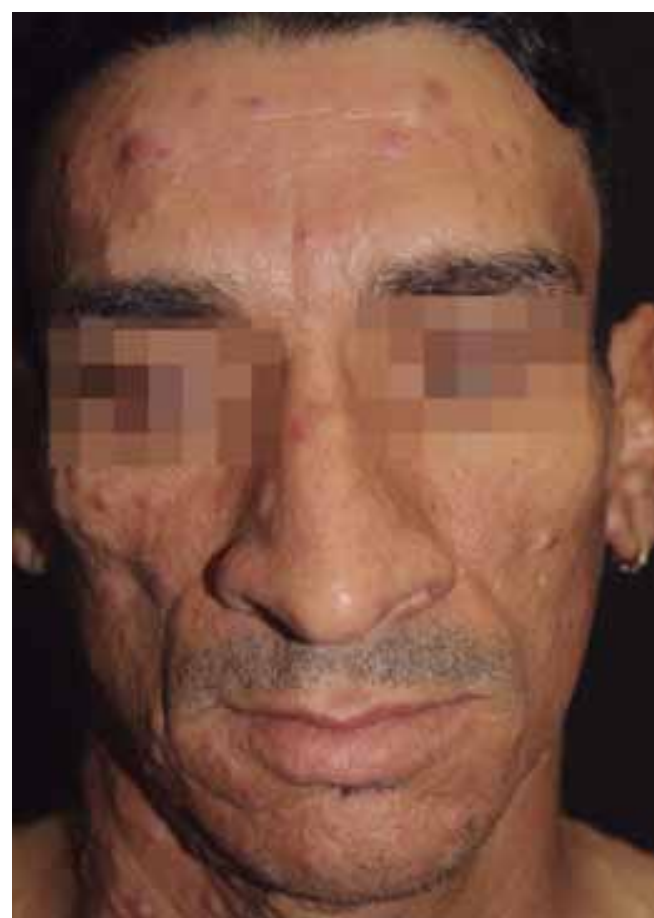

Figure 2:

Facial lesions

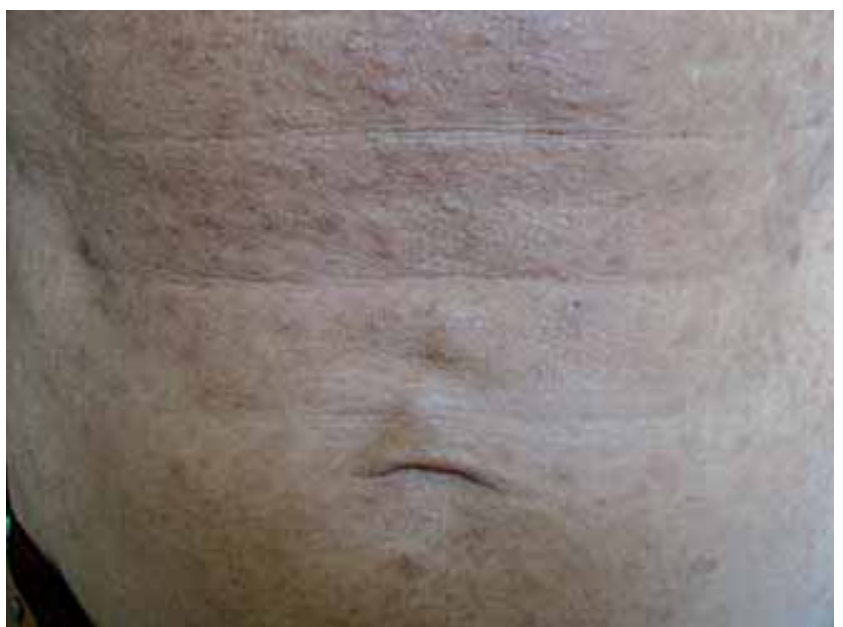

Figure 3: Papules and nodules on the abdomen. Similar lesions were present throughout the body

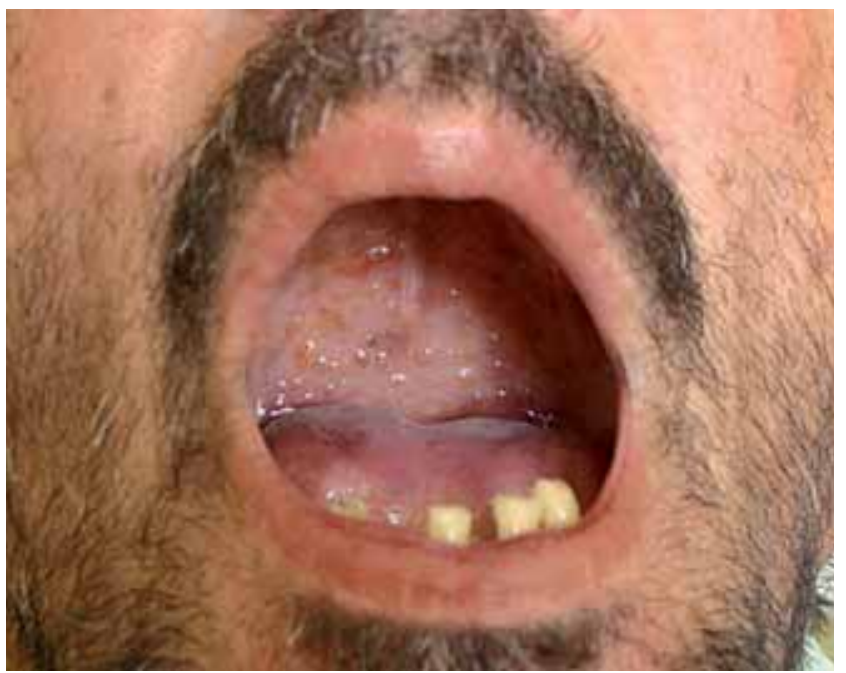

FIgURE 4: Lesions on the palate

history of visceral Leishmaniasis and since then, had been under prophylactic therapy with amphotericin $B$. At that point, the CD4+ cell count was 56 cells $/ \mathrm{mm}^{3}$, while two months before skin lesions developed, the CD4+ cell count was 108 cells $/ \mathrm{mm}^{3}$. Leishmania $\mathrm{sp}$ amastigotes were present on the myelogram, while the PCR, using the RV1 and RV2 primers, was positive in peripheral blood. The patient was treated with $\mathrm{Li}$ possomal Amphotericin B, leading to complete resolution of the visceral and cutaneous condition.

\section{DISCUSSION}

We present two rare cases of disease association. The development of skin lesions in patients with $\mathrm{HIV} /$ Kala-azar coinfection has been described in two different situations. ${ }^{1,2}$ 
Cutaneous lesions can develop in the context of immune reconstitution inflammatory syndrome (IRIS), caused by Leishmania. ${ }^{1}$ IRIS comprises a group of disorders that occur after some degree of immune restoration, which results in pathological inflammation to pathogens and their antigens. ${ }^{3}$ Clinical manifestations depend on the agent involved. ${ }^{3,4}$ The diagnosis is clinical and opportunistic infections should be considered in the differential. ${ }^{4}$ In HIV-positive individuals, one essential criterion for diagnosis is that patients be receiving antiretroviral therapy, with strong virological and immunological responses, meaning an increase in CD4+ cell count from the baseline and a decrease in HIV RNA level. ${ }^{3}$

IRIS cases related to Leishmania generally present with post-kala-azar dermal Leishmaniasis (PKDL), with a mean $\mathrm{CD} 4^{+}$cell count of 175 cells $/ \mathrm{mm}^{3}$ when skin lesions emerge. ${ }^{1}$ Similarly to the classical form of PKDL, the ability to mount an immunologic response to the parasite still present in skin has been implicated in the development of cutaneous lesions. ${ }^{5}$ Papules and nodules that are commonly located on the cephalic region typically occur at variable moments once the visceral disease is cured. ${ }^{6}$ Case 1 is an example of PKDL in the context of IRIS, as demonstrated by the increasing CD4+ cell counts and the good immunologic response, confirmed by the positive Montenegro's skin test. Furthermore, the patient did not show signs of visceral involvement, which would be expected in a case of visceral Leishmaniasis with secondary skin involvement.

Another possible dermal presentation of the $\mathrm{HIV} /$ kala-azar co-infection is the emergence of disseminated, cutaneous lesions during an active, visceral Leishmaniasis episode ${ }^{1}$. The most common symptoms of kala-azar in HIV-positive individuals are paleness (91.4\% of cases) and fever (85.9\% of cases). ${ }_{7}$ Moreover, patients with active infection habitually present moderate to severe immunosuppression and the mean $\mathrm{CD}^{+}$count is between 44 and 123 cells. ${ }^{8,9,10}$

Patient 2 presented signs of visceral involvement caused by Leishmania and his CD4+ cell count was decreasing. This data support the diagnosis of a kala-azar episode with secondary skin involvement in a patient with progressive immune depletion.

\section{REFERENCES}

1. Antinori S, Longhi E, Bestetti G, Piolini R, Acquaviva V, Foschi A, et al. Postkala-azar dermal leishmaniasis as an immune reconstitution inflammatory syndrome in a patient with acquired immune deficiency syndrome. Br J Dermatol. 2007;157:1032-6.

2. González-Beato MJ, Moyano B, Sánchez C, González-Beato MT, Pérez-Molina $J A$, Miralles P, et al. Kaposi's sarcoma-like lesions and other nodules as cutaneous involvement in AIDS-related visceral leishmaniasis. $\mathrm{Br} \mathrm{J}$ Dermatol. 2000;143:1316-8.

3. Elston JW, Thaker H. Immune reconstitution inflammatory syndrome. Int J STD AIDS. 2009;20:221-4

4. Huis in 't Veld D, Sun HY, Hung CC, Colebunders R. The immune reconstitution inflammatory syndrome related to HIV co-infections: a review. Eur J Clin Microbiol Infect Dis. 2012;31:919-27.

5. Ridolfo AL, Gervasoni C, Antinori S, Pizzuto M, Santambrogio S, Trabattoni D, et al. Post-kala-azar Dermal Leishmaniasis During Highly Active Antiretroviral Therapy in an AIDS Patient Infected with Leishmania infantum. J Infect. 2000;40:199-202.

6. Zijlstra EE, Musa AM, Khalil EA, el-Hassan IM, el-Hassan AM. Post-kala-azar dermal leishmaniasis. Lancet Infect Dis. 2003;3:87-98.

7. Lima IP, Müller MC, Holanda TA, Harhay M, Costa CH, Costa DL. Human immunodeficiency virus/Leishmania infantum in the first foci of urban American visceral leishmaniasis: clinical presentation from 1994 to 2010. Rev Soc Bras Med Trop. 2013;46:156-60.

8. Jarvis JN, Lockwood DN. Clinical aspects of visceral leishmaniasis in HIV infection. Curr Opin Infect Dis. 2013;26:1-9.

9. Alexandrino-de-Oliveira P Santos-Oliveira JR, Dorval ME, Da-Costa Fd, Pereira GR, da Cunha RV, et al. HIV/AIDS associated visceral leishmaniasis in patients from an endemic area in Centralwest Brazil. Mem Inst Oswaldo Cruz. 2010;105:692-7.

10. Souza GF, Biscione F, Greco DB, Rabello A. Slow clinical improvement after treatment initiation in Leishmania/HIV coinfected patients. Rev Soc Bras Med Trop. 2012;45:147-50.

\author{
M AILING ADDRESS: \\ D aniel Holanda Barroso \\ Rua A rnóbio M arquês 310 \\ Santo A maro \\ 50100-130 - Recife - PE \\ Brazil \\ E-mail: danielhbarroso@gmail.com
}

H ow to cite this article: Barroso DH, Silva CEF, Vasconcelos ACDP, Cavalcanti SMM, Brito MEF, Medeiros ACR. Post-Kala-azar dermal Leishmaniasis in two different clinical contexts. An Bras Dermatol. 2015;90 (3 Suppl 1):S108-10 